epithelial cell layer from its immunoregulatory capacity.

What are the implications of these findings for the understanding of immune responses to respiratory viral infections in human disease? We know that, in the airways of infants with respiratory syncytial virus bronchiolitis, there is massive production of proinflammatory cytokines $^{89}$ and chemokines ${ }^{1011}$ and recruitment of inflammatory cells. ${ }^{12}$ It is difficult in clinical studies which use bronchoalveolar lavage to assess the relative contribution of AECs and recruited inflammatory cells to cytokine and chemokine production in the airways. However, indirect evidence, such as comparing the amounts of mRNA for these mediators in the cell pellet (which does not contain viable epithelial cells) with protein detected in the supernatant, suggests that even several days after the initiation of lower airway infection, AECs are actively producing inflammatory mediators. ${ }^{11}$ It is not clear whether the massive inflammation observed in the airways of infants with viral bronchiolitis represents an appropriate and necessary response to infection, or whether it signifies local immune dysregulation which enhances disease in these infants. ${ }^{13}$

Dysregulation of local immune responses following respiratory viral infection has been shown in asthma. Exacerbations of asthma are frequently initiated by common cold viruses, most commonly rhinoviruses. Infection of asthmatic AECs with rhinoviruses, compared to normal AECs, has shown that the former have limited ability to produce
IFN $\beta$ and IFN $\gamma \cdot{ }^{14}{ }^{15}$ This results in impaired apoptotic responses and increased viral replication which was reversed by exogenous IFN $\beta .{ }^{14}$ This type I interferon deficiency is highly correlated with severity of asthma exacerbations. ${ }^{15}$

The work of these two groups will lead to revisions of current concepts and provide important pointers for further research into the role of AECs in local immune regulation. These investigators have correctly redirected our attention to what happens in normal healthy epithelial cells so that we can understand better the consequences of releasing professional immune cells from inhibition by AECs. If - as the work by Mayer et al suggeststhese findings are replicated in human cells, in diseases such as asthma is there dysregulation of the homeostatic responses? Do aberrations in the delicate homeostatic control mechanisms result in over-exuberant inflammatory responses to infection which manifest as severe viral bronchiolitis or pneumonia? Is there maturation of these responses in early life when respiratory viral infections are frequent and symptomatic? We are beginning to understand that, in health, the airway epithelium is like a duck-calm on the surface but paddling furiously underneath.

Competing interests: None.

Thorax 2009;64:277-278. doi:10.1136/thx.2008.099630

\section{REFERENCES}

1. Cruickshank SM, McVay LD, Baumgart DC, et al. Colonic epithelial cell mediated suppression of CD4 T cell activation. Gut 2004:53:678-84.
2. Wang H, Su Z, Schwarze J. Healthy, but not RSVinfected, lung epithelial cells profoundly inhibit T-cell activation. Thorax 2009;64:283-90.

3. Raz E. Organ-specific regulation of innate immunity Nat Immunol 2007;8:3-4.

4. Mayer AK, Muehmer M, Mages J, et al. Differential recognition of TLR-dependent microbial ligands in human bronchial epithelial cells. J Immunol 2007:178:3134-42.

5. Melmed G, Thomas LS, Lee N, et al. Human intestinal epithelial cells are broadly unresponsive to Toll-like receptor 2-dependent bacterial ligands: implications for host-microbial interactions in the gut. $\mathrm{J}$ Immunol 2003;170:1406-15.

6. Hayashi T, Beck L, Rossetto C, et al. Inhibition of experimental asthma by indoleamine 2,3-dioxygenase. J Clin Invest 2004;114:270-9.

7. Mayer AK, Bartz H, Fey F, et al. Airway epithelial cells modify immune responses by inducing an antiinflammatory microenvironment. Eur J Immunol 2008;38:1689-99.

8. McNamara PS, Flanagan BF, Selby AM, et al. Proand anti-inflammatory responses in respiratory syncytial virus bronchiolitis. Eur Respir $J$ 2004;23:106-12.

9. McNamara PS, Flanagan BF, Baldwin LM, et al. Interleukin 9 production in the lungs of infants with severe respiratory syncytial virus bronchiolitis. Lancet 2004;363:1031-7.

10. Fletcher JN, Smyth RL, Thomas HM, et al. Respiratory syncytial virus genotypes and disease severity among children in hospital. Arch Dis Child 1997; 77:508-11.

11. McNamara PS, Flanagan BF, Hart CA, et al Production of chemokines in the lungs of infants with severe respiratory syncytial virus bronchiolitis. J Infect Dis 2005;191:1225-32.

12. McNamara PS, Ritson P, Selby A, et al. Bronchoalveolar lavage cellularity in infants with severe respiratory syncytial virus bronchiolitis. Arch Dis Child 2003;88:922-6.

13. McNamara PS, Smyth RL. The pathogenesis of respiratory syncytial virus disease in childhood. $\mathrm{Br}$ Med Bull 2002;61:13-28.

14. Wark PA, Johnston SL, Bucchieri F, et al. Asthmatic bronchial epithelial cells have a deficient innate immune response to infection with rhinovirus. J Exp Med 2005;201:937-47.

15. Contoli M, Message SD, Laza-Stanca V, et al. Role of deficient type III interferon-lambda production in asthma exacerbations. Nat Med 2006:12:1023-6.

\title{
Human lung mast cell heterogeneity
}

\section{Peter Bradding}

Mast cells are found throughout the human body, both at mucosal surfaces and in the connective tissue of all organs. In fact, they are present in all classes of vertebrates including amphibians, reptiles, birds and mammals, and it has been estimated that the storage of histamine in vertebrate mast cells and its use as an inflammatory mediator was established in

Correspondence to: Professor P Bradding, Department of Respiratory Medicine, Glenfield Hospital, Groby Road, Leicester LE3 9QP, UK; pbradding@hotmail.com primitive reptiles (Lepidosauria) about 276 million years ago. ${ }^{1}$ This suggests that they mediate functions essential for life rather than representing a vestigial remnant of the immune system. Indeed, mast cells have been implicated in the regulation of many diverse homeostatic and pathological processes. For example, potential beneficial activities include defence against microbial infection with activation of both innate and acquired arms of the immune system, resistance to the effects of toxic venoms and roles in wound healing. ${ }^{2}$ Conversely, they are implicated in the pathophysiology of many diverse diseases such as atherosclerosis, ${ }^{4}$ allergy and asthma, ${ }^{5}$ pulmonary fibrosis $^{6}$ and rheumatoid arthritis. ${ }^{7}$

Mast cells are able to achieve these diverse tissue effects through the release of numerous vasoactive and bronchospastic autacoid mediators (histamine, leukotriene C4 (LTC4), prostaglandin $\mathrm{D}_{2}$ $\left(\mathrm{PGD}_{2}\right)$, serine proteases (tryptase, chymase), cytokines and chemokines. ${ }^{2}$ The release of these mediators is not "all-ornothing", but the pattern of molecules released is often tailored to the tissue insult. For example, using gene arrays, Okumura and colleagues showed that activation of cord blood-derived mast cells with anti-IgE, lipopolysaccharide (LPS), LPS + interferon $\gamma$ (IFN $\gamma$ ) or IFN $\gamma$ alone induced both core responses but also 
stimulus-specific responses. ${ }^{8}$ Furthermore, activation by LPS, for example, is able to induce cytokine secretion but not degranulation. ${ }^{9}$ It therefore seems likely that the normal role for the mast cell is to sense its external environment, ready to respond early to a tissue insult with an appropriate pattern of gene expression and mediator release aimed at initiating a programme of inflammation and repair. It is when this stimulus is chronic and does not abate that ongoing mast cell activation becomes harmful, promoting tissue remodelling and fibrosis.

Mast cells originate in the bone marrow as undifferentiated CD34+, CD117+ progenitor cells. These precursors mobilise to the peripheral circulation through poorly understood mechanisms, and then migrate into their destination tissue where they terminally differentiate under the influence of the local cytokine milieu, particularly stem cell factor. ${ }^{10}{ }^{11}$ Importantly, not all mast cells are the same, and they exhibit marked heterogeneity. This is evident across species, within different organs within the same species, and even within the same organ. ${ }^{12}{ }^{13}$ Heterogeneity is evident with respect to ultrastructure, receptor expression, mediator content, immunological and non-immunological activation, and pharmacological responsiveness. The factors leading to this heterogeneity are multifactorial and include interactions with the tissue matrix and resident cells such as fibroblasts which profoundly alter their phenotype, but it is also possible that progenitors are committed to a particular phenotype early in their development. ${ }^{14}$

Two common mast cell phenotypes recognised in humans are identified by their protease content. One population contains only tryptase $\left(\mathrm{MC}_{\mathrm{T}}\right)$ while a second contains tryptase, chymase, carboxypeptidase A and cathepsin G $\left(\mathrm{MC}_{\mathrm{TC}}\right) .{ }^{15} \mathrm{~A}$ rare third population containing only chymase $\left(\mathrm{MC}_{\mathrm{C}}\right)$ has also been reported. ${ }^{16}{ }^{17}$ The factors responsible for the development of these proteasespecific phenotypes are not well defined and are dependent on the source of the progenitors. ${ }^{14}$ It is also still not clear whether one phenotype can change to another, but the remarkably rapid conversion of $\mathrm{MC}_{\mathrm{TC}}$ cells to $\mathrm{MC}_{\mathrm{T}}$ has been reported in co-culture with human airway epithelium. ${ }^{18}$ The $\mathrm{MC}_{\mathrm{T}}$ phenotype is typically found at mucosal surfaces such as the nasal and bronchial epithelium in rhinitis and asthma, respectively, ${ }^{17} 1920$ and the bronchial lamina propria in health and disease. ${ }^{1720}$ In contrast, the $\mathrm{MC}_{\mathrm{TC}}$ phenotype favours connective tissues such as normal skin, ${ }^{19}$ the airway smooth muscle bundles in asthma ${ }^{21}$ and atherosclerotic lesions. ${ }^{22}$ The expression of different proteases among mast cells and the varying anatomical location of these cells indicates that they will have distinct roles, but these remain poorly defined.

In this issue of Thorax, Andersson and colleagues $^{23}$ have performed a detailed immunohistochemical and morphological phenotypic analysis of mast cells in "normal" human lung from lung resection specimens and bronchial and transbronchial biopsies from normal subjects (see page 297). In large airways, small airways, alveoli, pulmonary vessels and pleura, they analysed mast cell size and shape and expression of tryptase, chymase, FceRIa, interleukin-9 receptor (IL9R), histidine decarboxylase, 5-lipoxygenase, LTC4 synthase, renin, vascular endothelial growth factor (VEGF) and basic fibroblast growth factor (FGF). They showed a marked variability in the size and shape of cells at different sites, with large $\mathrm{MC}_{\mathrm{TC}}$ and small $\mathrm{MC}_{\mathrm{T}}$ evident particularly in pulmonary vessels. In terms of shape, $\mathrm{MC}_{\mathrm{TC}}$ were more circular than $\mathrm{MC}_{\mathrm{T}}$ in all compartments except the alveoli. There was some marked variability in the distribution of $\mathrm{MC}_{\mathrm{TC}}$ and $\mathrm{MC}_{\mathrm{T}}$ and their contents. In keeping with previous studies, $\mathrm{MC}_{\mathrm{T}}$ were the dominant cell in the airways and alveoli. Airway smooth muscle, where $\mathrm{MC}_{\mathrm{TC}}$ predominate in asthma, was not analysed but $\mathrm{MC}_{\mathrm{TC}}$ were more common in the pleura. The authors could not comment on whether they recognised any chymaseonly mast cells described by others due to the staining protocol used. ${ }^{16} 17$ The expression of the high-affinity $\operatorname{IgE}$ receptor and histidine decarboxylase was relatively high in airway $M C_{T}$ and $M C_{T C}$, but virtually absent in alveolar mast cells. Renin was highly expressed in pulmonary vascular $\mathrm{MC}_{\mathrm{TC}}$ but not elsewhere. Basic FGF and VEGF were expressed in airway, alveolar and pulmonary vascular $\mathrm{MC}_{\mathrm{T}}$, and large airway and pulmonary vascular $\mathrm{MC}_{\mathrm{TC}}$

Slight caution is required in the interpretation of the results presented. Mast cell mediators, enzymes and receptors were identified by immunohistochemistry using a panel of predominantly polyclonal antibodies. Mast cells are notoriously "sticky" due their high proteoglycan content, so it would have been reassuring to see appropriate isotype controls for the various antibodies used. That said, to some extent the different antibodies used act as controls for each other. The proportion of $\mathrm{MC}_{\mathrm{T}}$ to $\mathrm{MC}_{\mathrm{TC}}$ in airways and alveoli are broadly in line with previous studies, although the proportion of $\mathrm{MC}_{\mathrm{TC}}$ in the large airways was lower than that reported by others, ${ }^{17}{ }^{19}$ raising the question as to the efficiency of antigen retrieval for chymase. Although the data suggest some major variation in the expression of some proteins such as renin and FceRI $\alpha$, some of the other apparent differences are not so marked. Since there is no assessment of the intraobserver and interobserver variability of the immunohistochemical analysis, it is not clear to what extent some of the less marked differences might relate to variability in the assay. Furthermore, multiple comparisons have been made, although these have been allowed for statistically. Analysis of cell shape was undertaken using image analysis. Again there is no information on reproducibility, and there could be worries that the different sizes and shapes recorded might be related to the plane of section analysed. The authors have addressed this issue by also examining longitudinally sectioned tissue and using a stereological approach. Furthermore, the marked differences evident in the size and shape of $M C_{T}$ versus $M C_{T C}$ in the same tissue compartment suggest that these results are robust.

So what does this study tell us about lung mast cell biology? It is evident that human lung mast cells as a whole are a very heterogeneous population of cells. This has been evident from past studies, ${ }^{17} 192425$ but the current study extends these findings. It is perhaps not surprising that the phenotype of mast cells will be tailored to specific roles in various tissue microcompartments. For example, cells interacting with airway epithelial cells are likely to have different "aims" from those interacting with airway smooth muscle or vascular endothelium. What this study does not tell us is whether the phenotype of an individual mast cell is plastic, and whether it changes in disease. Both seem likely as the activation-dependent pattern of gene expression in fairly homogenous mast cell populations such as those from cord blood is highly specific to the stimulus, ${ }^{8}$ and mast cells in lung parenchyma in idiopathic pulmonary fibrosis are the dominant cells expressing basic FGF, although this growth factor was notably absent in alveolar mast cells in the current study. ${ }^{6}$ Furthermore, when mast cells are co-cultured with epithelial cells, there is a rapid switch from the $\mathrm{MC}_{\mathrm{TC}}$ to $\mathrm{MC}_{\mathrm{T}}$ phenotype, ${ }^{18}$ again suggesting marked plasticity. 
It is clear that mast cells expressing different mediators, enzymes and receptors will have different functions, but what those exact roles are is not known and can only be guessed at from the current study. Nevertheless, cells which do not express FceRI are unlikely to respond to allergen, while those expressing renin are likely to influence cardiovascular function. While it may be possible to isolate individual populations based on their receptor expression, at present it is not possible to do this with respect to intracellular contents, so determining their precise function will be a challenge. Others, however, have shown variability in lung mast cell density and size and examined their response to IgEdependent activation, but these studies did not examine the anatomical location of these cells. ${ }^{24}$ Interestingly, enzymatically dispersed parenchymal human lung mast cells fractionated using countercurrent elutriation were shown to range in size from 8 to $20 \mu \mathrm{m}$, with smaller diameter mast cells consistently releasing less histamine and $\mathrm{PGD}_{2}$ than large mast cells following IgE-dependent activation. ${ }^{24}$ This differential mediator release could not be explained by cell surface $\operatorname{IgE}$ content which was similar in mast cells of all sizes. Furthermore, the concentration of anti-IgE for maximum histamine release was the same for mast cells of all sizes, suggesting similar receptor function and density. This and other studies ${ }^{26}$ do not tally with the observation of Andersson that parenchymal lung mast cells do not express FceRI, suggesting that their immunohistochemical staining procedure might lack sensitivity.

In summary, the study by Andersson and colleagues demonstrates clearly the extensive heterogeneity of human mast cells within a single organ - in this case, the lung. This is likely to extend well beyond the current findings, and there is a huge challenge ahead to unravel the precise function of these different mast cell phenotypes in both health and disease.

\section{Competing interests: None.}

Thorax 2009;64:278-280. doi:10.1136/thx.2008.106427

\section{REFERENCES}

1. Mulero I, Sepulcre MP, Meseguer J, et al. Histamine is stored in mast cells of most evolutionarily advanced fish and regulates the fish inflammatory response. Proc Natl Acad Sci USA 2007;104:19434-9.

2. Bradding $\mathbf{P}$, Holgate ST. Immunopathology and human mast cell cytokines. Crit Rev Oncol Haematol 1999;31:119-33.

3. Kalesnikoff J, Galli SJ. New developments in mast cell biology. Nat Immunol 2008;9:1215-23.

4. Kovanen PT. Mast cells and degradation of pericellular and extracellular matrices: potential contributions to erosion, rupture and intraplaque haemorrhage of atherosclerotic plaques. Biochem Soc Trans 2007;35:857-61

5. Bradding $\mathbf{P}$, Walls AF, Holgate ST. The role of the mast cell in the pathophysiology of asthma. J Allergy Clin Immunol 2006;117:1277-84.

6. Inoue $\mathbf{Y}$, King TEJ, Tinkle SS, et al. Human mast cell basic fibroblast growth factor in pulmonary fibrotic disorders. Am J Pathol 1996;149:2037-54.

7. Eklund KK. Mast cells in the pathogenesis of rheumatic diseases and as potential targets for antirheumatic therapy. Immunol Rev 2007;217:38-52.

8. Okumura S, Kashiwakura J, Tomita $\mathrm{H}$, et al. Identification of specific gene expression profiles in human mast cells mediated by Toll-like receptor 4 and FceRI. Blood 2003;102:2547-54.

9. Varadaradjalou S, Feger F, Thieblemont N, et al. Toll-like receptor 2 (TLR2) and TLR4 differentially activate human mast cells. Eur $\mathrm{J}$ Immunol 2003:33:899-906.

10. Ishizaka T, Mitsui H, Yanagida M, et al. Development of human mast cells from their progenitors. Curr Opin Immunol 1993;5:937-43.

11. Jensen BM, Akin C, Gilfillan AM. Pharmacological targeting of the KIT growth factor receptor: a therapeutic consideration for mast cell disorders. Br J Pharmacol 2008;154:1572-82.
12. Irani AM, Schwartz LB. Mast cell heterogeneity. Clin Exp Allergy 1989;19:143-55.

13. Welle M. Development, significance, and heterogeneity of mast cells with particular regard to the mast cell-specific proteases chymase and tryptase. J Leuk Biol 1997;61:233-45.

14. Irani AA, Craig SS, Nilsson G, et al. Characterization of human mast cells developed in vitro from fetal liver cells cocultured with murine 3T3 fibroblasts. Immunology 1992;77:136-43.

15. Irani AM, Schwartz LB. Human mast cell heterogeneity. Allergy Proc 1994;15:303-8.

16. Weidner N, Austen KF. Ultrastructural and immunohistochemical characterization of normal mast cells at multiple body sites. J Invest Dermatol 1991;96:26-30S.

17. Bradding $\mathbf{P}$, Okayama $\mathrm{Y}$, Howarth $\mathrm{PH}$, et al. Heterogeneity of human mast cells based on cytokine content. J Immunol 1995;155:297-307.

18. Hsieh FH, Sharma P, Gibbons A, et al. Human airway epithelial cell determinants of survival and functional phenotype for primary human mast cells. Proc Natl Acad Sci USA 2005; 102:14380-5.

19. Irani AA, Schechter NM, Craig SS, et al. Two types of human mast cells that have distinct neutral protease compositions. Proc Natl Acad Sci USA 1986;83:4464-8.

20. Bentley AM, Jacobson MR, Cumberworth V, et al. Immunohistology of the nasal mucosa in seasonal allergic rhinitis: increases in activated eosinophils and epithelial mast cells. J Allergy Clin Immunol 1992;89:877-83.

21. Brightling CE, Bradding P, Symon FA, et al. Mast cell infiltration of airway smooth muscle in asthma. N Engl J Med 2002;346:1699-705.

22. Jeziorska M, McCollum C, Woolley DE. Mast cell distribution, activation, and phenotype in atherosclerotic lesions of human carotid arteries. J Pathol 1997;182:115-22.

23. Andersson CK, Mori M, Bjermer L, et al. Novel sitespecific mast cell subpopulations in the human lung Thorax 2009:64:297-305

24. Schulman ES, Kagey-Sobotka A, MacGlashan DW $\mathrm{Jr}$, et al. Heterogeneity of human mast cells. $\mathrm{J}$ Immunol 1983:131:1936-41.

25. Forsythe $\mathbf{P}$, McGarvey LP, Heaney LG, et al. Adenosine induces histamine release from human bronchoalveolar lavage mast cells. Clin Sci 1999:96:349-55.

26. MacGlashan D Jr. Single-cell analysis of Ca++ changes in human lung mast cells: graded vs. all-ornothing elevations after IgE-mediated stimulation. J Cell Biol 1989;109:123-34.

\section{Respiratory disability: what is it, how can we measure it, what causes it and is it important?}

\section{Philip Harber}

Respiratory disability is a significant health outcome that has important implications

Correspondence to: Professor P Harber, Division of Occupational and Environmental Medicine, David Geffen School of Medicine at UCLA, 10880 Wilshire Blvd, \#1800, Los Angeles, CA 90024, USA; pharber@ ucla.edu both for the individual patient and for society. First, "disability" represents the actual impact of the disease on the patient's life. While "impairment" (eg, loss of $200 \mathrm{ml}$ forced expiratory volume in $\left.1 \mathrm{~s}\left(\mathrm{FEV}_{1}\right)\right)$ is an abstract concept, patients are directly impacted by the ability to work or care for themselves (ie, respiratory disability) Second, functional status as manifested by respiratory disability is an integrated measure of health status and can be an effective indicator of response to treatment. Third, by working together, physicians, patients and employers may institute specific interventions to ameliorate respiratory disability. Fourth, in aggregate, disability for work due to respiratory disease has significant societal impact on overall work productivity of a society. Fifth, estimates of disease burden or years of life saved by medical interventions are commonly adjusted for the degree of disability using disability-adjusted life years. ${ }^{1}$ Finally, in many countries, regulations specify methods of evaluating the magnitude of 